\title{
CORPOS E CICLOS DA VIDA SANUMÁ-YANOMAMI*
}

\author{
Sílvia Guimarães \\ Universidade de Brasília - Brasil
}

Resumo: Esta etnografia sobre os Sanumá, subgrupo yanomami do alto rio Auaris, estado de Roraima, explora aspectos centrais de sua vasta e complexa cosmologia. Discute a noção de corpo e os ciclos de vida onde estados especiais devem ser observados no processo de construção da pessoa.

Palavras-chave: corpo, cosmologia, Sanumá, Yanomami.

Abstract: This ethnography focuses on the Sanumá, a Yanomami subgroup located on the upper Auaris River, in the northernmost state of Roraima in Brazil. It explores central aspects of their vast and complex cosmology by discussing the concept of body and life cycles where special states related with the construction of the person must be observed.

Keywords: body, cosmology, Sanumá, Yanomami.

Este artigo discute a corporalidade sanumá que passa por processo constante de metamorfose provocado pela vivência ou quebra de regras sociais ao mesmo tempo em que apresenta a formação da pessoa e seu ciclo de vida. Os Sanumá compõem um dos subgrupos da família linguística yanomami, que inclui também os Yanam, Yanomae e Yanomamö (Migliazza, 1967). Estão localizados nos dois lados da fronteira Brasil-Venezuela. O grupo de Auaris, onde foi realizada esta pesquisa, está localizado no noroeste do estado de Roraima.

* Este trabalho é uma releitura de parte da minha tese de doutorado (Guimarães, 2005) e compreende pesquisa que está sendo desenvolvida entre os Sanumá-Yanomami. 


\section{A diversificacão dos seres}

Para entender a teoria da corporalidade sanumá é necessário compreender o processo de transformação vivenciado pelo cosmos, onde os seres não surgem a partir do nada, eles se fazem do que já existe. Novos corpos, novos espaços, novos tempos são como reciclagens, produtos de operações sobre o que já está dado. No início, parecia reinar a amorfia, não havia inimigos ou animais, mas só os Sanumá ainda indefinidos. Com o surgimento dos dois irmãos Omawö e Soawö, heróis transformadores, intensificaram-se os processos de diferenciação, de transformação e criação do cosmos e seres, que continuam até hoje.

Depois que a primeira humanidade acabou devido ao canibalismo desenfreado desencadeado por um Sanumá-onça, Soawö, fez novamente os Sanumá, mas como entes sem tonalidades, de matéria amorfa. No entanto, essa matéria revelou ter a capacidade de transfigurar-se: bastava sofrer manipulações em sua forma ou inserir-se em redes de socialidade, vivenciando novas regras sociais, para que o processo de metamorfose se instaurasse. Forças disruptivas que movimentam o cosmos agiram no sentido de catalisar esse processo e, assim, a "matéria primeira" diversificou-se e produziu várias entidades. Nesse movimento de diferenciação, os Sanumá foram se definindo, fazendo-se mais humanos.

Portanto, sofreram, e ainda sofrem, várias transfigurações quando experimentam novos e diversos comportamentos ou provocam mutilações e manipulações em seus corpos. Essas transfigurações são os principais processos de diferenciação dos seres. Assim, a cada uma nova criatura há, necessariamente, uma nova corporalidade, novos costumes e uma nova ocupação espacial. Essa transformação do "ser" acontece no movimento (tanto no sentido de deslocamento quanto de mudança qualitativa) desencadeado por essa matéria, na passagem da potência ao ato. Portanto, "ser" não é só o que existe, "em ato". Ser é também o que "pode ser", a virtualidade, a potência. Dessa maneira, não é surpresa para os Sanumá uma substância ter novas características em novas ocasiões. A potencialidade de o "ser" existir, de se tornar "ato", está no movimento da matéria. Nesse sentido, os brancos, por exemplo, surgiram e foram interpretados como originários da dinâmica desse movimento do ser, isto é, da matéria-prima que é o Sanumá. 
Os Sanumá utilizam a expressão ixiwanihiolima para explicar as transformações rápidas, imediatas, pelas quais passaram e se tornaram animais, criaturas da floresta, plantas venenosas, cupinzeiros, colmeias. Nessa expressão, a partícula ixiwani indica "de maneira confusa, caótica". Portanto, hábitos marcantes de outras criaturas, como, por exemplo, andar sozinho durante a noite, podem indicar um processo de transfiguração. A quebra de regras sociais também provoca transformações; por exemplo, cometer incesto, isto é, não seguir a rígida interdição de copular com a sogra ou tia paterna provoca, inevitavelmente, a transfiguração da pessoa em preguiça.

Nas narrativas sobre a formação da população do cosmos, o corpo é também manipulado, experimenta outras formas até transfigurar-se. $\mathrm{O}$ caso do Sanumá que se metamorfoseou em veado exemplifica tal situação. De acordo com os Sanumá, o ancestral do veado comia pupunha e se sujava com as cascas, quando brigou com o genro por não ter ido buscar mais pupunha. Com raiva, começou a se limpar com o dente de um animal, e fazia tanta força que acabou afinando sua perna grossa. Assim, transformou-se em um veado e saiu correndo pela floresta.

Diante desses processos de metamorfose, a pessoa deve saber controlar suas maneiras ao longo de sua existência, visando à moldagem do corpo em direção a uma maior definição. No caso do aperfeiçoamento da condição humana, um evento marcante aconteceu em um local denominado saula tulia, onde, após uma grande guerra, ocorreu o primeiro ritual de reclusão do matador e a subsequente dispersão dos Sanumá em grupos de agnatos rumo ao nordeste de seu território. O que sobressai nos relatos sobre aquela guerra é que a vida em sociedade se tornou mais definida depois da mesma. É como se a socialidade tivesse adquirido uma alta resolução: os Sanumá diversificaramse, grupos patrilineares coalesceram e atividades guerreiras passaram a informar as transformações humanas, incluindo a construção da pessoa.

No texto clássico de Seeger, DaMatta e Viveiros de Castro (1979), a corporalidade assume um papel central na noção de pessoa de grupos indígenas sul-americanos, pois essa se inscreve na fabricação do corpo. O caso dos Sanumá não é diferente, pois para se fazerem mais humanos, os corpos tiveram que ser elaborados. Essa discussão vem sendo aprofundada na antropologia. Segundo Viveiros de Castro (1996, p. 128), para o pensamento indígena, o conceito de corpo figura em um plano intermediário entre a subjetividade 
formal das almas e a materialidade substancial dos organismos; refere-se a um conjunto de afecções ou modos de ser que constituem um habitus.

A contribuição da etnografia sanumá está na noção de corpo, que contém, na sua própria materialidade, a subjetividade do sujeito. O locus dessa subjetividade é real, material, físico, pois é tão corpóreo quanto o corpo físico. Assim, o conjunto de afecções, de que trata Viveiros de Castro (1996), materializa-se como substância corporal, como veremos a seguir.

\section{0 corpo sanumá}

Para os brancos, há sempre uma oposição entre corpo e alma, sendo esta última não corpórea e onde se concentram a consciência do sujeito, a memória, as reflexões e os sentimentos. Percebe-se a alma como essencialmente oposta ao corpo material e visível. Pois bem, essa oposição ou a ideia de uma alma não faz qualquer sentido para os Sanumá, para quem todas as porções da pessoa, visíveis e invisíveis, são substâncias físicas. Aquilo que "supomos" ser a alma porque é imaterial, invisível e refratária aos sentidos, para os Sanumá nada mais é do que pura materialidade, ou melhor, uma camada concreta que faz parte do corpo. Para eles, não é possível propor uma alma separada de um corpo como componentes separados do ser.

A intencionalidade consciente (agency) e os sentimentos da pessoa estão na carne, na pele, no cabelo, que replicam fisicamente no corpo interior denominado pili õxi. Este é uma réplica do corpo exterior nele inserido e locus do sentir, pensar e sofrer dores físicas. Trata-se de um outro "órgão", uma parte a mais do corpo. Nessa porção corpórea interior, unem-se matéria e subjetividade. Contudo, enquanto outras partes que compõem o organismo humano são visíveis, o pili õxi é invisível aos não xamãs. Os Sanumá são enfáticos em afirmar que as porções do corpo, tanto visíveis quanto invisíveis, são matérias, substâncias físicas, que não precisam ser vistas por todos para existirem, basta que os xamãs as vejam. Ao mirar as coisas, os xamãs afirmam a sua concretude. É o "ver xamânico" que as transforma em substâncias físicas.

Rodrigues (2008, f. 267) observou que os Javaé não concebem uma distinção entre corpo/matéria e alma/mente/sujeito, pois os pensamentos, memória e sentimentos não são abstrações opostas à materialidade do corpo, mas 
“estão 'dentro', fundidos com a essência da carne, como se fossem a própria matéria". Também os Sanumá enfatizam a materialidade de uma parte do corpo onde a pessoa sente e pensa. Como veremos, denominam de pili õxi ou õxi de essa porção corpórea, onde são expressos os sentimentos, o pensamento e se manifestam as doenças que são curadas pelos xamãs. A especificidade sanumá está no fato de que essa parte do corpo é uma réplica do corpo visível, do conjunto corporal formado de órgãos e vísceras. Seria melhor definir o pili oxxi como um "corpo interior", que os não xamãs não veem, mas cuja invisibilidade laica não o transforma em alma, ou qualquer outra noção de incorporalidade. Na cura, os seres auxiliares do xamã podem lavar esse corpo interior, tocá-lo, mexê-lo, o que basta para provar a sua materialidade. A visibilidade xamânica garante a existência do pili õxi como substância física. Consequentemente, a pessoa sanumá supõe um conjunto que vai além da noção dual corpo-alma. Os dados etnográficos ao longo da próxima seção esclarecerão melhor essa questão.

\section{Compartilhando substâncias}

A teoria da concepção sanumá segue a ideia da patrilinearidade que rege a transmissão da condição de membro de um grupo (Ramos, 1990). É o sêmen (moxilipö) do pai que faz a criança, assim, os filhos de ambos os sexos compartilham com ele uma mesma substância. De modo a identificar quem é filho de quem, diz-se que o genitor é aquele que "fez" (tabalima) a criança e a mãe, a que a "abraçou" (hãkoboma) ou "amamentou" (sakaboma). A mulher grávida é denominada xipinabi, o que parece derivar do termo xipo, "carregar". À primeira vista, a mãe figura como um simples receptáculo, mas veremos que ela também terá uma participação na formação da criança.

Durante a gravidez, se a barriga cresce muito rápido, os Sanumá insinuam que a mulher copulou com outros homens, pois a gravidez acelerada é um indicativo de adultério. O acúmulo de vários espermas acelera a formação da criança. Um jovem pai explicou que a criança será a principal prejudicada quando vários homens copulam com uma grávida, pois aqueles que contribuem para a formação da criança devem seguir certas restrições alimentares e não devem se ausentar da aldeia para que ela cresça saudável. 
Sobre a participação feminina na gravidez, uma mulher explicou que uma grávida acusada de manter relação sexual com outros homens defendese afirmando que sua barriga cresceu rápido porque ela tomou muito chibé. De acordo com os Sanumá, tanto o chibé quanto o sêmen auxiliam no crescimento da criança dentro da mãe. O chibé é uma bebida feita exclusivamente pelas mulheres; caso não haja mulheres na aldeia, os homens ficam sem bebê-lo. É feito do beiju da mandioca brava esfarelado na água em temperatura ambiente até ser dissolvido completamente e tomado numa cuia. Há uma variação quente do chibé que deixa o líquido mais grosso e homogêneo, de consistência cremosa. O que interessa aqui é o fato de os Sanumá enfatizarem que essa bebida auxilia na formação da criança, portanto, age conjuntamente com o sêmen. De acordo com os Sanumá, coisas que são manipuladas por uma pessoa acabam marcadas por ela. ${ }^{1}$ Essas marcas são partes do corpo, portanto, carregam sua essência. $\mathrm{O}$ chibé feito exclusivamente pela mulher terá sua "marca" como o sêmen tem a "marca" do homem, embora não na mesma intensidade. Por conseguinte, a mãe passa um pouco da sua substância corpórea ao filho, que o fará desenvolver-se e criar uma identificação com ela, uma vez que a criança fará parte do grupo patrilinear do pai, que se opõe ao seu. Como alimento produzido pela mulher, o chibé é associado ao leite materno que, por sua vez, é associado ao sêmen. Quando a criança nasce, o leite materno é tão essencial para sua vida como o sêmen foi para o feto. Assim, o sêmen e o leite materno são substâncias, fluidos corporais que desenvolvem, produzem a pessoa, e o chibé será um alimento especial que participa na formação da criança.

De acordo com um jovem pai,

O sêmen do pai parece água, leite. O pai copula com a mãe e vai depositando o sêmen. Assim, a criança vai aparecendo, as partes da criança vão surgindo, primeiro aparecem os olhos, depois a pele, o cabelo, as pernas, os braços, o pulmão, o fígado, o coração, o sangue, os ossos [...] Tudo vai sendo feito, até mesmo o pili oxxi.

1 Ver discussão sobre a extensão da corporalidade sanumá sobre pegadas, objetos, roças e casas construídas por um Sanumá em Guimarães (2005). 
A constituição final da criança, quando está pronta para nascer, é o conjunto de todas as partes reunidas, incluindo o õxi. A expressão sanumá para denominar o corpo humano, pili pewö (todos os componentes do corpo), indica esse conjunto. Portanto, em vez de uma palavra que signifique o que queremos dizer por corpo, designa-se a reunião de todas as partes que o compõem. Para denominar cada parte do corpo, o prefixo pili- é acrescentado ao nome correspondente dessas partes: o braço é pili poko, o coração é pili koso, a pele é pili ise, a boca é pili kai e etc. Todo o corpo reunido (pili pewö kokapali) equivale à pessoa.

Por conseguinte, quando digo corpo - numa tradução reconhecidamente imperfeita - estou me referindo à noção sanumá de reunião das partes que formam a pessoa e não a uma estrutura básica, uma matéria principal, una e indivisível. A ideia de conjunto e não de unicidade advém do fato de que são as múltiplas porções de sêmen a cada copulação que fazem os diversos componentes corporais. Há porções muito específicas, visíveis somente aos xamãs, mas todas resultam desse processo de concepção que conjuga o sêmen e o chibé, e sem ressonância com o que entendemos por organismo humano ou constituição do corpo. A próxima seção discute cada um desses componentes especiais com o intuito de compreendermos a teoria nativa da corporalidade.

\section{Do mesmo se faz o outro}

Nesta seção, trato de uma parte específica do corpo sanumá, já mencionada, o pili õxi, localizada no seu interior. O pili õxi é formado de cabeça, tronco, braços, fígado, sangue, carne, olhos, unhas, ossos, enfim, ele tem a mesma aparência e substância material da forma corporal exterior. Como as outras partes, esta também foi feita das copulações ao longo da gravidez. Uma de suas especificidades é ser o locus onde se concentram as faculdades do sujeito de pensar, sentir e criar, mas que não transcende a matéria, pois é como um outro corpo, substância física, introduzido no envoltório corporal. Outra de suas especificidades é ser a única parte da forma corporal humana que persiste após a morte, não é destruída e se transfigura no morto (heno polepö de). Assim, o pili oxxi traz em si a sua própria negação: metamorfoseia-se no morto, a alteridade radical por excelência. Antes de tratar dessa transfiguração do pili õxi em morto, será discutida a sua especificidade enquanto núcleo do ser humano. 


\section{O pili õxi}

À primeira vista, pareceria que o pili õxi é o que nós entendemos como alma, que se opõe ao corpo. Entretanto, enquanto para nós a alma está dentro do nosso físico porque é fluida, imaterial e, por isso, capaz de inserir-se na materialidade de qualquer objeto, para os Sanumá o pili õxi é um duplo do corpo, uma substância física e concreta. É como se duas matérias físicas ocupassem o mesmo espaço ao mesmo tempo, contrariando, portanto, nossas leis da física e noções a respeito das propriedades da matéria. Nesse sentido, não há o conceito de "impenetrabilidade da matéria" na teoria nativa da corporalidade. Lévy-Bruhl (1985) chamou a atenção para essa lógica de povos não ocidentais e sua capacidade de desenvolver o que ele chamou de "participação mística", ou seja, a possibilidade de dois corpos ocuparem simultaneamente o mesmo lugar.

Quando perguntei aos Sanumá se o pili õxi é fluido, evanescente, capaz de atravessar ou ser atravessado por objetos, eles negaram veementemente e afirmaram que ele é tão consistente quanto o corpo que vemos e com o qual interagimos. Para explicar a extensão física do pili õxi, ou seja, sua capacidade de ocupar um lugar no espaço, eles o comparam ao morto (heno polepö de), que também é um composto sólido, físico. Essa comparação faz sentido para os Sanumá, uma vez que o morto é a metamorfose do õxi de ${ }^{2}$ e é mais fácil perceber a sua materialidade, agindo livremente, pois ele não tem outras porções do corpo acopladas a ele como acontece com o pili õxi.

Quando a pessoa morre, os seus parentes cuidam para que todo o cadáver e aquilo que lembra o morto sejam destruídos, somente o õxi não se desfaz. Os Sanumá enfatizam o fato de o morto, enquanto ente material, ir caminhado para sua casa, deixando pegadas como nós fazemos, tocando e movendo os objetos. Afirmam que, por mais que a maioria dos Sanumá não veja esses rastros e o caminho que os mortos seguem, o xamã é capaz de vê-los e de interagir com toda a realidade física que se forma em volta deles. A visibilidade

2 Geralmente, os Sanumá designam de õxi de e não pili õxi, quando se referem a essa parte do corpo que se metamorfoseou no morto. 
xamânica, assim como a visibilidade tematizada por Merleau-Ponty (2003, p. 128), apalpa com o olhar as coisas. Nesse sentido, este autor afirma que

o visível à nossa volta parece repousar em si mesmo. É como se a visão se formasse em seu âmago ou como se houvesse entre eles e nós uma familiaridade tão estreita como a do mar e da praia. No entanto, não é possível que nos fundemos nele nem que ele penetre em nós, pois então a visão sumiria no momento de formar-se, com o desaparecimento ou do vidente ou do visível.

Os Sanumá acreditam na concretude do pili õxi, pois o xamã é capaz de vê-lo, da mesma maneira que todos veem as coisas. Além dos xamãs, seus seres auxiliares e os sai töpö (criaturas da floresta) também conseguem ver e manipular o pili õxi. Constantemente, esses últimos raptam-no ou algumas de suas partes, o que faz a pessoa adoecer ou morrer. Quando o xamã diz que uma criatura da floresta raptou o coração ou a pele de uma pessoa, ele está se referindo ao coração e à pele do pili oxxi. Ou quando explica que a pessoa está doente devido à substância venenosa que lançaram no seu interior, esse interior é o do pili oxxi. Portanto, volto a repetir: a percepção e manipulação xamânica conferem a essa parte do corpo sua substancialidade e realidade física. De acordo com um xamã:

O õxi de é como um outro dentro do Sanumá que vemos. Essa parte do Sanumá, o õxi de, não é capaz de atravessar pessoas e objetos. Ele tem materialidade, é uma réplica do corpo que vemos e está inserido nesse corpo. Trata-se de algo com carne [apertou o próprio braço], ele não é como um desenho, chapado no papel. ${ }^{3}$ Quando o Sanumá morre acontece uma transformação do õxi de. Ele se torna o heno polepö de e vai caminhando para a morada dos mortos, por uma trilha que passa no meio da floresta. Ele caminha e deixa marcas pelo caminho. O xamã e os seres auxiliares conseguem ver tanto o õxi de quanto o heno polepö de. Eles conseguem ver as marcas, as pegadas do heno polepö de.

Antes de abordar mais detidamente o morto, enquanto uma transfiguração do õxi, cabe apresentar outras características do pili oxxi. Todas as pessoas têm um pili óxi que se modifica ao longo da vida, envelhece, da mesma

3 Disse isso quando tentei perguntar se o pili õxi era do tamanho do Sanumá e da forma do Sanumá, isto é, se tinha largura, espessura, comprimento, altura e massa corpórea.

Horizontes Antropológicos, Porto Alegre, ano 16, n. 34, p. 261-286, jul./dez. 2010 
maneira que a forma corporal exterior. A vitalidade localizada no oxxi indica que a pessoa está viva e saudável e permite-lhe conversar. O pensamento, as reflexões, as criações e os sentimentos estão também nessa substância física. Os Sanumá dizem que as crianças têm o õxi ignorante ou inconsciente (oxxi moodi); por sua vez, os velhos o têm mais alerta, hábil (oxxi pataxiba ai de mosawi - o õxi dos anciãos é outro, mais alerta). Por isso, os velhos sabem mais, contam melhor as histórias.

A aparência física e a maneira como um adulto se expressa e se relaciona, os estados emocionais em que, frequentemente, se encontra, que estão concentrados no pili õxi, indicam a história de vida, o modo como vivenciou, compreendeu as coisas e envelheceu. Os anciãos de ambos os sexos devem ser magros, ter rugas, o que indica que trabalharam muito, fizeram muitas coisas e, portanto, aprenderam muito ao longo da vida. Por outro lado, a obesidade de um velho significa que ele foi preguiçoso, não produziu muito, não fez grandes roças, não foi um grande caçador. Ter sido generoso, destemido, corajoso, bem-humorado, ter chorado e vingado seus mortos indica a sapiência dos velhos. Em Auaris, os anciãos com esse perfil, magros e bem-humorados, são vistos como os mais sábios, respeitados e bons xamãs. Opõem-se aos gordos e que, coincidentemente ou não, são pessoas de trato mais difícil, mal-humoradas, zangam com facilidade, o que lhes dá a imagem de não saberem das coisas e não serem bons xamãs. Nessa noção nativa de senilidade, esse ideal do ancião magro está também relacionado com modificações que ocorrem no corpo ao longo da vida. Veremos que a pessoa se situa em um contínuo que vai do "encharcado" ao "seco", pois deve perder a substância que a umedece.

Agir, relacionar-se com os outros e ter ânimo são ações que dependem do pili õxi. Por exemplo, quando o pili õxi de uma pessoa é raptado, ela não consegue sair da rede, trabalhar, comer, fazer qualquer coisa, ou, quando um parente morre, o pili õxi fica tão triste que a pessoa não consegue trabalhar. $\mathrm{O}$ õxi é também o que faz o Sanumá perceber o mundo e as coisas, õxi tabamo kule (o oxxi vê, sabe das coisas). Nele está a capacidade de reflexão. Por exemplo, um dia, eu pretendia fazer uma troca com um rapaz e disse-lhe que ia pensar. No outro dia, ele veio me perguntar: "Au õxi taba?" ("seu interior já sabe, já tem a decisão, o conhecimento?"), fazendo uma referência direta ao meu corpo interior para saber se eu havia me decidido ou pensado. No õxi estão as sensações, os sentimentos, as dores, os pensamentos experimentados pela pessoa e é onde ela sente os efeitos das enfermidades, que devem ser curadas 
pelos xamãs. As manifestações do oxxi, as formas de expressão concentradas nessa substância física são variadas e revelam que na sua materialidade está o sujeito e também as sensações físicas, como, por exemplo, sentir náusea e, depois de vomitar, se sentir aliviado. Esse alívio está no pili oxxi, na matéria que o forma, portanto, ele sente. Estas são algumas das expressões usadas pelos Sanumá para designar o que a pessoa sente ou pensa:

- está com frio: õxi wadi;

- está leve (isso acontece, por exemplo, depois de o matador vomitar as substâncias do morto que estão em seu interior; ele se sente leve): õxi hetehe;

- está triste: oxxi pi honipo;

- está feliz: õxi pi mïnïha.

Não há a ideia de um sujeito que pensa, sente e intui abstraído da materialidade do corpo, pois, no pili oxxi, está concentrada a vitalidade da pessoa, são construídos os pensamentos e formam-se os sentimentos. A manifestação do pili oxi depende de ele estar acoplado a todas as outras partes do corpo, que são como seu invólucro. Caso o pili õxi seja retirado desse conjunto ou invólucro, a pessoa perde o ânimo, o ímpeto, a vontade e poderá morrer.

\section{0 morto (heno polepö de)}

Já foi apontada uma característica específica do pili õxi, a de metamorfosear-se em morto. Com essa transfiguração, a materialidade do pili õxi adquire uma outra propriedade, a de imortal. Sobre essa relação entre õxi e morto, um homem adulto afirmou:

[...] O Sanumá daqui [em Auaris] é sanumá, nós somos sanumá. O õxi de está no Sanumá vivo, ele faz parte do corpo [pili pewö]. É como outro dentro, que nós não vemos. O õxi de é composto de todas as partes que vemos nos Sanumá, é composto de fígado, coração, carne, sangue, ossos, pele, cabelos, unhas, braços, pulmão... Depois que o Sanumá morre, surge o henö polepö de. São duas coisas distintas, primeiro, porque o õxi de não é outro [tiko de] como o nö polepö de; segundo, porque o õxi de está no Sanumá vivo e o nö polepö de aparece quando o Sanumá morre. Mas os dois têm algo em comum, pois são vistos somente pelo xamã, os outros Sanumá não conseguem vê-los. Quando a pessoa 
morre, todo o seu corpo é destruído [realizam a cerimônia funerária de cremação e consumo das cinzas] e só resta o nö polepö de que surge a partir do õxi de. A pessoa morre e só resta essa porção dela que se torna outro. O nö polepö de tem cabelo, braços, olhos, pele, tem tudo. Toca-se nele, assim como se toca o corpo da pessoa viva. Não é como vapor que sai de uma água que ferve. O heno polepö de não morre nunca, sempre se rejuvenesce.

Um xamã confirmou as características do õxi e do morto:

O espírito auxiliar do xamã do teso [beija-flor] vê o õxi de, procura as doenças nele. A pele do õxi é mais clara, enquanto a pele externa da pessoa é mais escura. Os ossos interiores do õxi são vermelhos. O õxi de é äpädi ["mole", isto é, mortal] enquanto o heno polepö de é amatoxi ["duro", imortal]. O morto é tão diferente como um sai de [criatura da floresta], portanto, é outro, não é mais Sanumá.

A capacidade de transformar-se em inimigo, do Mesmo originar o Outro, é um ponto importante na teoria nativa da corporalidade que se assemelha à de vários outros indígenas. No caso dos Sanumá, com a morte essa transfiguração é evidente, pois o morto, que não é imaterial ou evanescente, está contido no corpo interior e provém dele. Embora o heno polepö de tenha a aparência do corpo exterior e do oxxi, sua substância física é distinta das várias partes do corpo do Sanumá vivo. A transfiguração modifica a qualidade da matéria do morto, que passa a ser "duro" (amatoxi) e, consequentemente, imortal. A modificação substancial do morto revela que se trata de um outro ser, que deve ser evitado pelos Sanumá, pois é perigoso, pode agredir as pessoas. O õxi e heno polepö de ocupam posições extremas e opõem-se quanto a: qualidade "mole" (äpädi)/qualidade "dura" (amatoxi), mortal/imortal, mesmo/outro, identidade/alteridade. O morto é o avesso do õxi.

Para que o processo de transformação do õxi em morto, ou para que o morto se torne inimigo, seja definitivo, seus parentes devem queimar o cadáver, destruir até mesmo as marcas, as impressões que, em vida, ele deixou em objetos, em construções, em plantações. Toda a sua corporalidade anterior deve ser extinguida no ritual funerário, quando o corpo é cremado, os ossos são pulverizados e as cinzas são consumidas. Caso contrário, ele sempre será atraído por essas porções do seu corpo de Sanumá que guardam sua memória. Sobre isso um homem explicou: 
Quando o xamã sonha ou usa alucinógenos, ele consegue ver o heno polepö de se aproximando da casa e manda-o ir embora. Os outros Sanumá não veem o heno polepö de, mas eles conseguem ouvir o barulho que ele faz ou podem vêlo metamorfoseado em outra criatura. Há um tempo atrás, estava na época da cerimônia funerária de uma mulher, quando seus parentes iam comer suas cinzas. Um dia, minha esposa foi pegar minhocuçu e viu uma cobra diferente com boca de tatu começando a entrar na terra. Era o heno polepö de da mulher que morreu, metamorfoseado [ixiwani] nessa criatura. A cobra dizia: "Tss, tss, tss." A pessoa morre e o heno polepö de pode voltar para sua roça, para trabalhar na roça. Quando nós ouvimos um barulho diferente na roça, mas não há ninguém lá, é o heno polepö de que voltou para trabalhar.

Os Sanumá de Auaris enfatizam o perigo e a agressividade do morto. Para entendermos porque ele se transforma em inimigo, uma negação categórica do ser sanumá, que o originou, temos que saber o que acontece com ele após a morte e sobre o seu processo de metamorfose. Isso tudo se passa em uma outra dimensão, paralela à que vivemos.

Imediatamente após a morte de uma pessoa, seu heno polepö de está por perto vendo os parentes chorar. Outros mortos também vêm ver a cremação com o recém-falecido, observam o cadáver na rede e pensam que é um queixada. Os Sanumá não os veem, não sabem o quão perto eles estão. Os mortos sentam-se próximo à pira crematória e observam os Sanumá que choram, queimam o cadáver e guardam os pedaços dos ossos carbonizados. No entanto, para os mortos, todo esse processo é visto como o de moquear uma caça. Eles fazem muitas perguntas aos Sanumá como, por exemplo, por que choram, se desejam muito comer toda a caça. Acham os Sanumá mesquinhos, pois pensam que estão chorando porque desejam muito a caça e não pretendem distribuí-la. Os mortos dizem que não querem nada, que os Sanumá podem ficar com tudo. Os espíritos auxiliares do xamã estão o tempo todo conversando com os mortos tentando controlá-los, pedem-lhes para não questionar os Sanumá, para ficar em silêncio, só observando. Os Sanumá não percebem a presença dos mortos, tampouco seus questionamentos, pois tudo se passa em uma dimensão não percebida por eles. É nessa impossibilidade da maioria dos Sanumá de interagir com os mortos que está o perigo. O xamã teme que estes se irritem com os Sanumá, que não lhes respondem, não são receptivos e generosos, mas os ignoram. O xamã é o único que, com o uso dos 
alucinógenos, pode interagir com os mortos. Se os xamãs não intervierem, os mortos podem ficar furiosos e agredir os Sanumá.

O morto que passa pela transfiguração exala um odor fétido. Como cheira muito mal, ele vai até a casa de Omawö (herói criador) para que este lhe dê um banho e retire esse odor. Após o banho, Omawö pede aos hutumosöliue töpö (ancestrais dos animais que vivem no céu, que dominam o avião) para guiar o morto até sua nova morada. O banho pode ser dado também por outros mortos, relacionados com o recém-falecido, que vêm buscá-lo. Depois do banho, o morto segue pelo longo e largo caminho que corresponde às pessoas do seu grupo patrilinear. Quando acontece alguma cerimônia funerária, os mortos retornam a casa dos Sanumá para ver o ritual por essas trilhas. Ao longo dessas há pousos para que possam descansar, se pintar e se enfeitar.

Assim como as trilhas, cada uma das casas nessa outra dimensão pertence a determinado grupo patrilinear. Tanto as casas quanto os animais e as plantas das roças dos mortos são $u k u d u b u$, isto é, duplos das coisas que existem no mundo dos Sanumá. Assim, se algum animal da floresta morre, seu $u k u d u b u$ será caça nessa região. Tudo o que há naquele local é cópia do que existe em vida. Portanto, em suas casas, os mortos caçam, pescam, cultivam plantas em suas roças da mesma maneira que os Sanumá fazem. Entretanto, não devemos imaginar que essa realidade que se forma com os mortos é imaterial, pelo contrário, esse mundo é concreto, os xamãs conhecem.

No meio do caminho, o morto pode querer desistir e retornar. Ele titubeia, mas é convencido pelos outros mortos a continuar. Há casos em que o morto realmente retorna antes de concluir a caminhada ou quando já se encontra na morada dos mortos, mas antes de comer a comida destes, ou seja, de concluir a transfiguração. Por outro lado, o morto que segue o caminho até o fim e chega à casa dos mortos e, imediatamente, come da comida e bebe o chibé feito por eles, transfigura-se. Assim, não há mais como reverter seu estado, pois passou a compartilhar da mesma substância desses outros e a se portar como eles.

Quando o morto chega a sua nova morada, vários outros vão recepcionálo, todos estão enfeitados. É um local agradável, todos são bonitos e permanecem sempre jovens. O próprio õxi do recém-falecido, quando morto, passa por um processo de rejuvenescimento.

O morto que faleceu há pouco tempo tenta atrair os seus parentes vivos para sua casa, ou seja, quer transfigurá-los em mortos. Durante o ritual funerário, que pode acontecer dentro de um ano ou mais, o morto sempre retorna 
para ver os Sanumá cremar, triturar e comer as suas cinzas e tenta atrair alguns dos seus parentes vivos para a nova dimensão em que se encontra. Quando os Sanumá sonham, um morto oferece-lhes a comida dos mortos, se alguém a come, transformar-se-á em morto. Os mortos têm vários alimentos aparentemente idênticos aos dos vivos, mas que contêm uma substância letal e podem transformar/alterar o estado das pessoas, de vivo para morto. Um ancião sanumá esclareceu sobre a agressividade do morto: "Parece que há um sai de [criatura da floresta] dentro do heno polepö de, pois ele é muito perigoso, os Sanumá não o querem por perto. Ele é semelhante a um sai de, que tenta matar o Sanumá."

Os mortos e toda a realidade que os envolve são letais, não se deve ter contato com eles. Por mais que tentem uma aproximação, é impossível manter qualquer tipo de interação ou de comunicação, há um distanciamento abrupto e radical, não é possível vê-los, não há meios de realizar diálogos cerimoniais, guerras, ou trocas. Nessa outra dimensão, que parece se assemelhar tanto à dos Sanumá porque é feita de réplicas do seu mundo, está o máximo da alteração do ser.

Se o pili õxi é a expressão maior da asserção do ser sanumá, por sua vez, o morto em que se transformou será a expressão máxima do inimigo, de quem é preciso se distanciar. Seguindo a lógica das transformações operadas no cosmos, ao final da vida de uma pessoa, seu pili õxi, até então sede das manifestações do ser humano, dá origem ao morto com seu potencial de grande agressividade.

\section{A profundidade do ser}

Anteriormente, vimos que o pili óxi é uma parte específica da forma corporal, inserida no seu interior e que é invisível à maioria das pessoas. Outras porções do corpo parecem envolvê-lo, ou melhor, suas materialidades penetram na materialidade do pili oxxi, acoplando-se a ela de maneira singular. Assim, a pele (pili ise), que todos vemos é a última dessas porções.

Uma característica da matéria que forma o pili õxi é ser tridimensional e suficientemente ampla para que outras substâncias possam se inserir nele. Trata-se de um conceito singular de espessura que indica a densidade, mas é mais do que isso. Enfatiza a profundidade do corpo do pili oxxi que pode 
estar vazio ou pode ser preenchido por outras substâncias. Portanto, enquanto composto material, ele tem uma espessura que permite a outras substâncias se inserirem nele, ao mesmo tempo em que sua materialidade penetra as outras partes que formam o corpo exterior. Desse modo, o pili oxxi pode estar acoplado a outras matérias, mas não deixa de ter textura e profundidade. O xamã vê e manipula essa matéria, apanha substâncias letais que lhe são inseridas por agressores.

A pele (pili ise) da pessoa é como o exterior de um recipiente que contém todas as outras partes do corpo, até mesmo o pili õxi. Os Sanumá chamam, por exemplo, a superfície de uma panela de pele e seu espaço interior de oxxi. Por sua vez, o pili õxi tem uma pele própria com a mesma função de invólucro. No interior do pili oxxi, podem estar tanto essas substâncias venenosas que deixam a pessoa doente quanto as marcas ou rastros deixados pelos agressores quando o raptam. Ao ser retirado do corpo, o oxxi poke (interior vazio) deixa o Sanumá enfermo. Ao concentrar substâncias letais, o õxi matihi (interior cheio) torna a pessoa inchada e igualmente enferma. Os ritos de reclusão existem para que a pessoa possa se restabelecer de substâncias que se acumulam nessa parte do corpo. Para entendermos o que acontece com os corpos nesses rituais, deve ficar clara a noção de profundidade do pili óxi que enfatizo, pois nela acontecerá a mudança corporal do recluso. Por exemplo, a jovem púbere retém muito sangue e o matador tem uma alta concentração de substâncias do morto no pili õxi. Todas essas substâncias são reais e cheias de significados e não apenas imaginárias, não apenas simbolizadas. Elas são vividas e criam realidades, como enfatizou Lévy-Bruhl (1985, p. 362).

Os Sanumá de Auaris têm uma noção clara de espessura, produzida pelo conjunto das partes visíveis e invisíveis. A ideia de contorno, relevo acentuado do corpo e do cosmos, isto é, de profundidade, necessariamente, indica que, além de as substâncias físicas do corpo se interpenetrarem, o pili õxi tem um interior onde substâncias se acumulam. Quando o xamã adquire sua visão especial e seus variados sentidos, ele percebe a materialidade, a profundidade e a tridimensionalidade do pili oxi, onde muitas coisas acontecem com a pessoa.

Essa noção de profundidade está também no cosmos, por isso, os xamãs conseguem ver dimensões dentro de uma dimensão, uma realidade dentro de outra, o corpo dentro do corpo, sem que um anule o outro. Corpos e dimensões do cosmos podem ocupar o mesmo espaço ao mesmo tempo porque há "suficiente profundidade para tudo". Por exemplo, o xamanismo acontece em uma 
dimensão que, simplificando, poderíamos descrever como imaterial, exclusivamente imaginária, invisível, mas que, na verdade, é descrita pelos Sanumá como uma materialidade e realidade, onde estão os seres auxiliares dos xamãs, criaturas da floresta e outros seres. Essa dimensão insere-se e dissemina-se na realidade onde os não xamãs se encontram. O mesmo vale para o sonho, que é uma dimensão que se expande e ocupa a realidade em volta da pessoa que dorme e onde tudo o que acontece nesse espaço terá consequências na vida em vigília. Portanto, as dimensões do sonho, do xamanismo e da vida cotidiana se interpenetram numa demonstração levibruhliana de que a lei da contradição do pensamento ocidental está longe de satisfazer as exigências da etnografia sanumá. E o pili oxxi tem essa profundidade e realidade no interior do corpo visível aos não xamãs.

Os cantos xamânicos esclarecem o que é esse encontro de dimensões. Nas sessões xamanísticas, os seres auxiliares cantam e seus cantos desenham a realidade de que tratam, de modo que o xamã vê os cantos, vê a realidade que eles retratam, os acontecimentos que ocorrem em lugares e tempos outros. O som do canto dos hekula töpö é como um filme tridimensional que penetra ou parece "inflar" uma outra realidade à vista do xamã, semelhante à "música visual" dos shipibos, mencionada por Gebhart-Sayer (1986), que é projetada pelos "espíritos/essências" nos olhos dos xamãs. Nesse povo, o choque dos cantos dos "espíritos" com os sons emitidos pelos xamãs produz imagens tridimensionais. Portanto, a tridimensionalidade concebida pelos Sanumá de Auaris difere da nossa por permitir a coexistência e interpenetrabilidade de matérias e realidades físicas.

Toda essa discussão da visão xamânica está relacionada com o corpo sanumá e com um de seus componentes, o pili õxi. Por mais que essa porção penetre na matéria do corpo visível, ele continuará a ter sua própria espessura e sofrer ações maléficas de vários agentes que podem causar a morte de uma pessoa.

O ciclo de vida sanumá só é compreensível quando abordamos o conceito sanumá de corporalidade, pois ao longo da vida de uma pessoa essa noção de corpo é tratada, manipulada, reclusa com o intuito de aperfeiçoá-la para tornar a pessoa mais humana. As situações liminares ou de risco na vida de uma pessoa devem-se, especialmente, ao desequilíbrio provocado pelo acúmulo de substâncias em seu corpo, ou melhor, nessa porção do corpo denominada pili oxi. Ter o controle sobre elas garante o devido processo de envelhecimento 
do ser, a não transfiguração e a não perturbação cósmica. Rituais de reclusão acontecem para garantir o controle do fluxo dessas substâncias, através de rígidas prescrições e restrições. Também para os Yanomae, Albert (1985) observou que esses ritos são seguidos à risca com o intuito de controlar a efusão de uma substância, o sangue, e, consequentemente, ter o controle da passagem correta do tempo (biológico, sociológico e cósmico).

\section{Liminaridade e ciclos da vida sanumá}

Logo após o parto, o recém-nascido vive uma situação de risco que requer de seus pais a sujeição a severas regras e interdições. É a primeira de uma série de situações liminares que a pessoa viverá. No caso do recém-nascido, ele depende de seus consubstanciais, pai e mãe, para evitar que sofra agressões de seres não humanos. Assim, o pai não deve ir à floresta, mas permanecer nas proximidades de casa para não ter contato com alguma criatura da floresta. A mãe, por sua vez, fica reclusa, devido ao sangue liberado no parto. Deve ficar sentada junto ao fogo por, aproximadamente, cinco dias, até que o sangue pare de fluir. Ao término desse período, ainda não pode tomar banho no rio, pois isso atrairia cobras furiosas e poderia provocar uma enchente que mataria toda a comunidade ou provocaria a transfiguração de todos em pequenos sapos. Por isso, ela deve buscar água no rio e banhar-se longe dele. $\mathrm{O}$ sangue que flui da mãe é a principal essência corporal que deve ser controlada nesse momento. Rapazes e moças evitam visitá-la devido à sua letalidade. Os mais velhos aguardam que mãe e filho se fortaleçam para ir vê-los, o que acontece quando o recém-nascido emite sons com maior intensidade, sinal de que pili õxi está saudável. As substâncias e os fluidos compartilhados por pai, mãe e recém-nascido levam-nos à reclusão em conjunto, à tríplice couvade, cada um à sua maneira.

Nas demais situações liminares - nos rituais de puberdade e do matador substâncias letais acumulam-se em excesso no pili õxi, o que exige a reclusão da pessoa e um rigoroso regime que controle a efusão desses fluidos. Veremos que o excesso desses líquidos deixa a pessoa "umedecida", mais corruptível, mais putrescível, mais äpädi ("mole”), isto é, expande-se a qualidade primeva ou original dos Sanumá, característica da árvore de ciclo de vida curto que Soawö, herói transformador, usou para fazê-los. 


\section{Rito de puberdade feminino (hokolomo)}

O sangue menstrual surgiu devido ao peixe poraquê que estava no interior da vagina da mulher e se partiu ao meio, o que a encheu de muito sangue. Após esse evento, a "mulher deve se sentar sempre" (sue de lobo xinamo), isto é, menstrua, assim, deve ficar sentada junto ao fogo doméstico, não deve ir à roça nem ao rio. À noite, ela pode deitar na sua rede, muito baixa, rente ao chão. Nesse estado especial, a mulher também deve evitar comer certas carnes de caça para não deixar o caçador sem pontaria.

$\mathrm{Na}$ menarca, a jovem entra em um estado liminar quando acumula em seu interior um excesso de substâncias perigosas (wazu). Elas deixam a menina "encharcada" e são liberadas no fluxo menstrual e na transpiração. As interdições e regras que a jovem deve seguir, nesse momento, são mais rigorosas que as dos outros fluxos. Deve passar pelo ritual de reclusão hokolomo para controlar essas substâncias. A expressão hokolomo deriva do verbo hokolo, que significa cercar, fazer um abrigo, levantar paredes de uma casa. A jovem fica reclusa em um abrigo hermeticamente fechado, sem qualquer contato com o exterior, enquanto seu sangue flui. Ela própria teme esse estado especial e reluta em avisar a mãe ou outra mulher que lhe é próxima. No entanto, assim que o sangue começa a escorrer, sua mãe a leva para casa, coleta palhas ou folhas, faz o abrigo de reclusão dentro da casa como um compartimento à parte e acende uma fogueira perto da qual a jovem permanecerá sentada.

Quando está em hokolomo, a moça não deve fazer movimentos bruscos. $\mathrm{Na}$ verdade, ela deve permanecer imóvel a maior parte do tempo, com as pernas esticadas, não pode ficar na posição confortável e rotineira de uma mulher quando está próxima ao fogo. Seu cabelo é raspado e todos os adornos retirados. Durante todo o rito, ela só veste uma pequena tanga, que, ao final, será jogada fora. Não conversa com ninguém nem toca o próprio corpo, pois por todos os poros é liberado um líquido letal juntamente com o sangue que flui. Por isso, sua mãe entrega-lhe um pauzinho com o qual ela se coça. $\mathrm{O}$ atrito de suas mãos e unhas pelo corpo faz o líquido que está sendo expelido retornar para seu interior, contaminando-a, o que pode matá-la. Deve comer pouco, somente os pedaços de beiju que sobraram da comida da família, pois seu interior já está "cheio" de substâncias, que devem ser liberadas ao longo da reclusão. A jovem emagrece, expelindo na menstruação e no suor esse acúmulo 
de substâncias. Usa um pauzinho também para pegar a comida, pois não pode tocar diretamente o alimento para não contaminá-lo. Toma chibé e não deve comer qualquer tipo de carne de caça. A justaposição de substâncias, ou seja, misturar outras à que já está em seu corpo pode provocar uma saturação letal.

A jovem deve permanecer nesse estado liminar por, aproximadamente, cinco dias, até o sangue parar de fluir. Terminada a menstruação, sua mãe usa folhas de hokolomoi hena, as mesmas usadas para fazer o tapume, para lavá-la longe do rio. Depois do banho, as folhas do abrigo são jogadas fora e a jovem senta-se perto do fogo doméstico, absolutamente em silêncio. No dia seguinte, será pintada e enfeitada com miçangas e retornará à vida social.

Os Sanumá qualificam a substância que encharca o pili õxi da jovem púbere de wazu (letal, venenosa). Ao ser expelido, toma forma de sangue e suor, e o fogo acesso no interior do abrigo auxilia no processo de secagem.

\section{Rito de puberdade masculino (poko manokoximo)}

A reclusão do jovem não é tão elaborada quanto a da moça e as restrições e prescrições que o rapaz deve seguir são mais atenuadas. Pode-se dizer que a versão masculina do ritual de puberdade feminino é o ritual de reclusão do matador. Mesmo assim, os jovens púberes tomam certos cuidados, pois também correm riscos. A expressão poko manokoximo refere-se ao desnudar (manokoximo) do braço (poko), ou seja, o jovem deve retirar as braçadeiras e os fios de algodão amarrados nos tornozelos e abaixo do joelho.

A mãe ou avó do menino avisa quando é o momento de realizar o rito. $\mathrm{O}$ início é marcado pelo "desnudamento do rapaz", quando todos os seus ornamentos the são retirados. Ele deve amarrar uma cinta de algodão e usar uma tanga de pano velho que será desfeita após o ritual. O cabelo é raspado e o couro cabeludo pintado de urucum. O rapaz deve ficar deitado em uma rede de cipó acima da de sua mãe ou avó, com o corpo esticado, não pode virá-lo para os lados e muito menos ficar em posição de descanso. Seus braços devem estar esticados ao longo do corpo durante todo o período em que ele estiver deitado. Não pode conversar e deve usar um pini (tabaco) pequeno entre os dentes e o lábio inferior para mudar sua voz, deixá-la como a de um homem adulto.

Semelhante à jovem púbere, o pili õxi do rapaz produz uma substância altamente letal que deixa sua matéria corpórea também excessivamente úmida. 
Assim, deve emagrecer e expelir o que já o está intumescendo perigosamente. O pouco alimento que lhe é dado deve ser consumido apenas parcialmente. Deve usar um pauzinho para se alimentar e coçar.

Após três dias, o responsável pela realização do rito leva-o para tomar banho no rio, apanha folhas para esfregá-lo e retira toda a substância líquida que impregna o seu exterior. Em seguida, passa urucum na sua pele e amarra braçadeiras novas. O jovem volta a falar e deve beber muito chibé.

Agora, está pronto para seguir outros homens adultos em longas excursões de caça. Ele já poderá obter uma mulher e realizar o suhamo (suha-genro e mo - agir como), ou seja, o serviço da noiva. Além disso, não correrá o risco de ter um tom desagradável na voz.

\section{Ritual do matador (kanenemo)}

Após matar o inimigo, o guerreiro fica com seu pili oxxi cheio do morto. Deve entrar em reclusão para digerir lentamente as substâncias exógenas isto é, a matéria corporal do morto - que estão em seu interior e controlar a sua efusão. Esse exocanibalismo impõe ao matador um rígido ritual com severas prescrições e proibições, que acontece ao mesmo tempo em que o cadáver da vítima está sendo manipulado por seus parentes na cerimônia funerária. Enquanto acontece a cremação do corpo, a pulverização dos ossos e o consumo das cinzas, o matador fica com o corpo quente, transpira mais ainda e a digestão da substância exógena passa a acontecer com rapidez.

A simultaneidade do exocanibalismo do matador e do tratamento do cadáver pelos parentes coincide com o intervalo de tempo necessário para acontecer a vingança. $\mathrm{Na}$ lógica da guerra, o matador agiu para vingar a morte de um dos seus e sabe que, por sua vez, os parentes de sua vítima o vingarão. $\mathrm{O}$ contra-ataque acontecerá a qualquer momento quando vivenciam esses ritos. Atualmente, esse se dá não por meio de represálias diretas, mas de técnicas mágicas/xamânicas. Muitas vezes, esses procedimentos atacam o kanene de surpresa, quando está em reclusão, fazem o fogo junto ao qual está sua rede explodir e ele também.

Voltando ao rito, morto o inimigo, o matador retorna a sua casa em silêncio absoluto. Quando está bem próximo, assovia como o gavião para anunciar a sua chegada e condição especial. Uma mulher relacionada ao matador, mãe 
ou esposa, prepara o tapiri de reclusão onde ele armará sua rede. Ela traz uma brasa e prepara o fogo que irá aquecê-lo. O matador tem um hálito fétido, ou melhor, todo o seu corpo exala um cheiro desagradável, pois o morto está em putrefação em seu interior. Ele está "digerindo" sua vítima, reduzindo-a em um líquido letal que será expelido por todos os seus poros. Os Sanumá enfatizam que o estado de kanenemo, ou estar "gordo e cheio do inimigo em seu interior" é motivo de regozijo.

O matador pinta o rosto de vermelho, e deve permanecer isolado em abrigo separado de sua casa, onde arma sua rede de cipó que trouxe já pronta da floresta, ao lado do fogo. Como o jovem púbere, o kanene deve ficar deitado e imóvel em sua rede, com os braços esticados ao lado do corpo ereto, vestido só com a cinta. Ele mesmo retirou as braçadeiras e perneiras. Quando não está na rede, senta-se em uma pedra, mas não pode tocar o chão com os pés. Não pode trabalhar. Ninguém se aproxima dele. A morte da vítima faz o matador engordar, seu pili õxi fica cheio do morto. É como se toda a corporalidade do morto formasse uma essência única, produto da digestão que sofre no interior do matador. Ao longo do rito, essa substância esvai-se no suor, na saliva, no vômito. Assim, a superfície do corpo exterior do matador fica suja com um tipo específico de wazu, substância letal e exógena que se esvai por todos os poros. A cabeça do matador tem muitos vermes que caem no chão, devido à digestão da carne pútrida do morto. Coça-se somente com um pauzinho pelos mesmos motivos dos jovens em reclusão.

Deve jejuar até à fome. A mãe ou a esposa cuida de sua alimentação especial. Pode comer só um pouco de bananas amassadas em uma cuia velha, sugando o mingau por um pequeno canudo. A comida é deixada sobre um pedaço de lenha, suas mãos estão poluídas pelo morto e ele deve ter muito cuidado para não se contaminar. A reclusão visa exatamente controlar a ingestão e expulsão das substâncias do morto para que não sejam reabsorvidas pelo matador e protegê-lo do envenenamento e da morte. Deve cuspir sua saliva, produzida em excesso, em uma pedra quente, colocada junto ao fogo, para que ela evapore, visto que contém também fluidos do morto. Ao evaporar, a saliva faz o barulho ("Tchẽi, tchẽi!") característico da gordura animal quando cai no fogo. Ele não deve cuspi-la diretamente no chão porque o minhocuçu, que vive embaixo da terra, pode engoli-la, uma pessoa pode caçá-lo e, assim, contaminar-se com o veneno. O tabaco usado entre os lábios deve ser jogado no fogo porque também está cheio de essências letais. O kanene tem sonhos 
perigosos, por isso deve ficar atento. Sonha que algum morto desconhecido o agride, bate-lhe, o que pode matá-lo. Sente frio quando seu mani de (réplica do corpo que surge nos sonhos) está em ação e só volta ao normal quando esse retorna ao corpo. Enquanto o cadáver está sendo cremado pelos parentes do morto, o matador fica com o corpo quente, com muito calor, lhe sai fumaça pelo nariz, o que o faz transpirar muito e ficar mais sujo ainda. Isso o ajuda na digestão e na expulsão dos fluidos do morto. Só pode tomar banho depois do término do rito.

No final da reclusão, o irmão do matador acompanha-o até uma cachoeira. Este se senta em uma pedra enquanto o irmão apanha mel. O matador deve beber todo o mel, o que o faz vomitar os restos do morto que ainda estão em seu interior. Na cachoeira, em uma forte corredeira que leva tudo embora, ele vomita o cabelo, a gordura, as unhas, os ossos, tudo do morto reduzido a uma substância. Nesse momento do rito, tudo que restou da vítima é expelido. O pili óxi do matador fica limpo após o vômito, que pode acontecer várias vezes, até esvaziar. Depois disso, o matador sente seu pili õxi vazio e leve.

O kanene volta para seu abrigo e deita-se mais um pouco. Pinta o rosto de vermelho novamente e aguarda mais alguns dias, para ter certeza que todas as substâncias do morto se esvaíram. Ao fim desse período, os anciãos de seu grupo verificam se a pintura está intacta, se não se apagou com as essências do morto que poderiam ainda estar nele. Se não houve transpiração e a pintura não se desfez, então não há mais resquício do morto no interior do matador, o ritual chegou ao fim, ele já pode tomar banho, quando esfrega folhas no corpo para retirar as substâncias do morto.

Com o banho, o matador deve cortar o cabelo. Senta em uma pedra, próxima ao rio, corta-o com o pole pole de, um tipo de bambu. Amarra uma pedra na rede que utilizou e a joga no fundo do rio, em um local de forte correnteza, onde apodrecerá. O matador corta seus pelos pubianos e coloca-os na árvore poloi. Faz um corte com facão no caule da árvore de tal maneira que o pedaço do corte não seja decepado, finca aí os pelos e os deixa lá, acompanhando o desenvolvimento da árvore, o aumento de seu perímetro. $\mathrm{O}$ cabelo cortado também deve ficar na árvore poloi. O matador sanumá joga fora o cinturão de algodão, veste um novo, enfeita braços e pernas e se pinta todo de preto. $\mathrm{O}$ tempo de reclusão do matador pode durar um mês ou mais. Além do desgaste da pintura vermelha na face do matador indicar a duração do rito, alguns Sanumá dizem que, no início do kanenemo, um homem adulto corta um cipó 
no alto de uma árvore e o tempo de crescimento do cipó, até alcançar o chão e arrastar-se, será o tempo em que o kanene ficará recluso.

Não passar pela reclusão é fatal tanto para o matador quanto para os seus parentes, pois ele pode intumescer cada vez mais até explodir, espalhando os restos do morto e contaminando todo o ambiente, ou pode morrer envenenado com o refluxo da substância mortífera. Sabemos que, na ontologia sanumá, cada forma corporal requer determinada maneira de agir, hábitos, modo de falar, modo de pensar, enfim, um específico modo de ser e, que, quando se assume uma nova corporalidade ou modo de agir, há o risco de ocorrer a transfiguração. Nesse sentido, o matador vive uma situação liminar de Sanumá/ onça, pois agir livre das prescrições e restrições do ritual de reclusão poderia provocar sua transfiguração em onça.

Os Sanumá dizem que o corpo humano segue um contínuo que vai do "encharcado" ao "seco". Esses mesmos estados definem as árvores de ciclo de vida curto, rapidamente corruptíveis (äpädi), e árvores de ciclo de vida longo (amatoxi). Os recém-nascidos são extremamente "moles" (äpädi), contêm muita gordura e têm "ossos que se quebram facilmente, como de uma galinha". No outro extremo estão os velhos, "magros", "secos", "duros" (amato$x i$ ), marcados por um esgotamento de fluidos, de gordura, daquilo que irriga a matéria sólida. A cada nova fase da vida em que a pessoa se transforma $(\mathrm{ku}$ pazo), ela seca cada vez mais. A corporalidade especial dos velhos se coaduna com o ideal da forma física e com a maneira como conduziram suas vidas. Os Sanumá dizem que os velhos que trabalharam muito, foram grandes guerreiros ou xamãs são magros (tabu winibi, pouca gordura) e duros (amatoxi), já os velhos que foram preguiçosos são gordos e moles (äpädi). Devido a essa característica ideal dos anciãos, os Sanumá enfatizam que seus cadáveres não liberam muito líquido quando são cremados como os dos jovens.

Os próprios Sanumá não fazem essa relação entre corpo humano e árvore, como estou associando, de maneira tão explícita como os canaques (Leenhardt, 1979). Esses melanésios utilizam uma "nomenclatura vegetativa" para definir as partes do corpo. Portanto, enquanto entre os melanésios essas associações estão explícitas na língua, no caso dos Sanumá as similitudes aparecem em sutis qualificativos empregados tanto para seres humanos quanto para árvores.

Taylor (1974) discutiu as nuanças e sutilezas das gradações das fases da vida sanumá, que significa mudanças tanto no corpo quanto nas suas maneiras, 
e as relacionou com proibições alimentares. Algumas dessas fases pelas quais as pessoas passam, ou "vêm a ser" (kupazo), são: ulu oxidi (bebê de colo), ulu (criança), moko/hixa (a jovem/o jovem adulto), patasoma/pata de (mulher/ homem adulto com filho), patasoma/pataxiba (anciã/ancião que não podem mais ter filhos). De acordo com esse autor, acontecimentos como começar a andar, ritos de puberdade, nascimento de filhos e menopausa marcam a passagem de uma fase para outra. Também marcam a transformação gradual da corporalidade da qualidade äpädi para a amatoxi. Essa transfiguração ao longo da vida esbarra em situações liminares quando substâncias endógenas ou exógenas desequilibram o corpo, como vimos.

As situações liminares - o parto, os rituais de puberdade e do matador - figuram como momentos quando o corpo fica excessivamente molhado, produz internamente ou recebe de fora substâncias que embebem, intumescem seu interior, que entra em um estado corruptível. O corpo do recluso passa a ter a qualidade encharcada, putrescível das árvores de madeira mole das quais o protótipo é a árvore escolhida por Soawö para fazer os Sanumá mortais. Por conseguinte, como os recém-nascidos, as pessoas que vivem a reclusão estão äpädi, moles, e, quando saem desse estado, elas estão amatoxi, duros, semelhantes aos velhos. Depois de passar corretamente pelo rito, a pessoa está seca, magra, por isso o jovem e o matador, ao término da reclusão, devem beber muito chibé. Com o tempo, eles voltam a ter a consistência adequada à fase de vida em que estão. Na morte, a pessoa sofre uma transformação definitiva, seu corpo deve ser cremado, e seu pili õxi se transforma no morto, adentrando uma outra dimensão e finalizando seu ciclo de vida.

\section{Referências}

ALBERT, B. Temps du sang, temps des cendres: représentation de la maladie, système rituel et espace politique chez les Yanomami du sud-est (Amazonie Brésilienne). Tese (Doutorado)-Université de Paris X (Nanterre), Paris), 1985.

GEBHART-SAYER, A. Una terapia estética. Los disenos visionarios del ayahuasca entre los Shipibo-Conibo. América Indígena, v. 46, n. 1, p. 189 $218,1986$. 
GUIMARÃES, S. M. F. Cosmologia sanumá: o xamã e a constituição do ser. Tese (Doutorado em Antropologia)-Instituto de Ciências Sociais, Universidade de Brasília, Brasília, 2005.

LEENHARDT, M. Do Kamo: person and myth in the Melanesian world. Chicago: University of Chicago Press, 1979.

LÉVY-BRUHL, Lucien. How natives think. Princenton: Princenton University Press, 1985.

MERLEAU-PONTY, M. O visivel e o invisivel. São Paulo: Perspectiva, 2003.

MIGLIAZZA, E. Grupos lingüísticos do Território Federal de Roraima. In: SIMPÓSIO SOBRE A BIOTA AMAZÔNICA, 1966, Belém. Atas... Rio de Janeiro: Conselho Nacional de Pesquisa, 1967. v. 2, p. 153-173.

RAMOS, A. Memórias sanumá: espaço e tempo em uma sociedade yanomami. São Paulo: Marco Zero; Ed.UnB, 1990.

RODRIGUES, P. de M. A. Caminhada de Tanyxiwei: uma teoria javaé da história. Tese (Doutorado)-Universidade de Chicago, Chicago, 2008.

SEEGER, A.; DAMATTA, R.; VIVEIROS DE CASTRO, E. A construção da pessoa nas sociedades indígenas. Boletim do Museu Nacional, v. 32, n. 1-2, p. 2-19, 1979.

TAYLOR, K. Sanuma fauna: prohibitions and classifications. Caracas: Fundación La Salle de Ciências Naturales, 1974. (Monografia 18).

VIVEIROS DE CASTRO, E. Os pronomes cosmológicos e o perspectivismo ameríndio. Mana, v. 2, n. 2, p. 115-144, 1996. 